\title{
Relationship between Particle Size Distribution of Low-Rank Pulverized Coal and Power Plant Performance
}

\author{
Rajive Ganguli and Sukumar Bandopadhyay \\ Department of Mining and Geological Engineering, University of Alaska Fairbanks, P.O. Box 755800, Fairbanks, AK 99775, USA \\ Correspondence should be addressed to Rajive Ganguli, rganguli@alaska.edu
}

Received 25 July 2011; Revised 4 December 2011; Accepted 5 February 2012

Academic Editor: Kalyan Annamalai

Copyright ( $) 2012$ R. Ganguli and S. Bandopadhyay. This is an open access article distributed under the Creative Commons Attribution License, which permits unrestricted use, distribution, and reproduction in any medium, provided the original work is properly cited.

\begin{abstract}
The impact of particle size distribution (PSD) of pulverized, low rank high volatile content Alaska coal on combustion related power plant performance was studied in a series of field scale tests. Performance was gauged through efficiency (ratio of megawatt generated to energy consumed as coal), emissions $\left(\mathrm{SO}_{2}, \mathrm{NO}_{x}, \mathrm{CO}\right)$, and carbon content of ash (fly ash and bottom ash). The study revealed that the tested coal could be burned at a grind as coarse as $50 \%$ passing 76 microns, with no deleterious impact on power generation and emissions. The PSD's tested in this study were in the range of 41 to 81 percent passing 76 microns. There was negligible correlation between PSD and the followings factors: efficiency, $\mathrm{SO}_{2}, \mathrm{NO}_{x}$, and $\mathrm{CO}$. Additionally, two tests where stack mercury $(\mathrm{Hg})$ data was collected, did not demonstrate any real difference in Hg emissions with PSD. The results from the field tests positively impacts pulverized coal power plants that burn low rank high volatile content coals (such as Powder River Basin coal). These plants can potentially reduce in-plant load by grinding the coal less (without impacting plant performance on emissions and efficiency) and thereby, increasing their marketability.
\end{abstract}

\section{Introduction}

Despite containing an estimated 5 trillion tons of a variety of coal [1], Alaska has only one operating coal mine, the Usibelli Coal Mine. The low-rank, high-volatile content coal produced by the mine has a low grindability, as indicated by its hardgrove grindability index (HGI). This can be an issue for the salability of the coal since power plants prefer coals that are easy to grind. A possible mitigation for the low grindability is less grinding, if the coal could be burned at a coarser grind without impacting power plant performance.

The rank and volatility of the coal are key to combustion. As many researchers agree, the lower the rank of coal, the more reactive it is [2-4]. The authors in [5] also found that rank influenced combustion properties of pulverized coal more than the maceral composition. In addition to the rank, [6] found that the quantity of volatile matter also impacted the ignition of the volatile matter, though there was no correlation between the actual content of the volatile matter and the ignition behavior [4, 7]. Additionally and directly relevant to this paper are the findings by $[8,9]$, who studied pulverized coal combustion of the low-rank high-volatile UCM coal to explore if it could be burned at a coarser particle size distribution (PSD) than the industry standard of $65-70 \%$ passing 76 microns (200 mesh). Both reported encouraging results. In this paper, the PSD is quoted in percentage passing 76 microns (200 mesh), similar to what is done in the power industry.

The preliminary study by [9] preceded the more detailed tests conducted for this paper. His study consisted of two tests, one at an average PSD of $42 \%$ and the other at an average PSD of $49 \%$. Each test in the preliminary study resulted in 24 samples (six samples per pipe-description in the next section); thus, the reported PSDs were averages of 24 samples. Multiple PSD samples were taken (according to the ASTM D-197 method) in each of the $3 \mathrm{hr}$ long tests. The test (major details from [9] are reproduced below for helping the reader) showed that there was no difference in electricity generation (in megawatts or MW). Following the proof of concept that the coal could be burned at coarser PSD without loss in power generation, a detailed study was undertaken to include important aspects such as repeatability of results, 


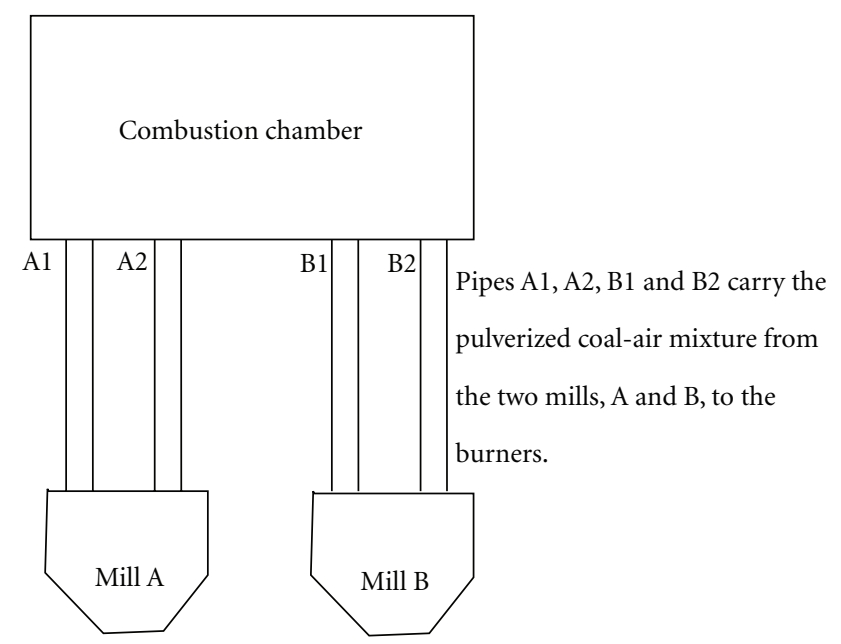

FIGURE 1: Mill (pulverizer) and combustion chamber layout (after [2]).

impact of quality of feed coal, impact on emissions, and carbon content of fly ash and bottom ash. This paper presents the results of the detailed tests. Note that additional information and data from the tests can be obtained from a publicly available report [10]. The implications of the study are important; though Alaska low-rank coal is burnt in very few plants, similar coals (such as those burning coals Powder River Basin in the United States) are burned in a significant number of plants worldwide.

\section{Description of Tests and Sampling}

The detailed tests were similar to what was done in [9], except that in these tests a lot more data was collected. The data collected in the 24 detailed tests, also conducted in Golden Valley Electric Association's Healy 28 MW Unit no. 1 as in [9], included (in addition to MW generated) raw feed coal quality, pulverized feed coal quality and PSD, fly ash and bottom ash characteristics, and emissions measurements. Figure 1 shows a schematic of the power plant.

Two Foster Wheeler MBF 19.5 mills, A and B, ground the raw feed coal into pulverized coal. The mills are air swept; that is, the pulverized coal is carried by air at $65.6^{\circ} \mathrm{C}(150 \mathrm{~F})$ to the combustion chamber through the four pipes $\mathrm{A} 1, \mathrm{~A} 2, \mathrm{~B} 1$, and $\mathrm{B} 2$. The grind size is altered by increasing or decreasing the air flow through the mill or by opening/closing the mill "classifiers." Each of the four pipes has a sampling port that was used for sampling pulverized coal. While most of the pulverized coal samples were collected by ASTM D-197 method, some samples were collected using ISO 9931 by a contractor. The reason for the change was that the research team damaged its sampling probe and had to hire a third party to collect the pulverized coal samples. Multiple pulverized coal samples were collected from each pipe during a test (typically 3 hours long) so that the PSD was representative of the duration of the test. As in [8], validity of PSD sampling was verified using the RosinRamler (RR) plots. The particle size, at which $36.8 \%$ of the flow is retained on the screen, or the $k$ value was estimated from the plots. The $k$ values for Tests 3 to 20 averaged about 100 microns, while those of Tests $21-26$ averaged 56 microns. Tests 1 and 2 are from the preliminary study [9].

The raw coal samples were collected from the feed stream of the two mills A and B. The data collected from the raw coal feed included proximate analysis and HGI. The data collected from the pulverized coal included PSD and proximate analysis. The fly ash and bottom ash were sampled for unburned carbon. The fly ash was sampled from fabric filters (bag houses), while the bottom ash was sampled from the bottom of the combustion chamber. Collecting representative bottom ash samples was very difficult as the bottom ash chamber was not designed for sampling. The flaming ash chamber had to be flooded, and the ash sample collected quickly as it left the chamber, while flames shot out of the open door from where the sample was collected. Additionally, the stack emissions were sampled (by a contractor) for $\mathrm{Hg}$ using the Ontario Hydro Method in two of the tests. Data on $\mathrm{NO}_{x}, \mathrm{SO}_{x}$, and $\mathrm{CO}$ were obtained using automated continuous emissions monitoring system from stack gases exiting the plant. Emissions controls in the plant consisted of fabric filters (bag houses) only. There were no wet scrubbers.

The PSD of the pulverized coal being burned is never known in real time. The plant operators manipulated the mill classifier vanes and primary air flow to increase or decrease the fineness of the grind. The vane and primary air flow were set at least two hours prior to a test to ensure stability of the grind during the test. The operating PSD for a test was only known after several weeks of the test. It was very difficult to run the plant at the settings required for some of the finer grinds. Therefore, the reader will notice very few tests at PSD finer than $65 \%$.

\section{Results and Discussion}

The data from the tests are shown in Tables 1, 2, 3, 4, 5, 6,7 . Tests 1 and 2 in the tables are from [9]. The reader will notice gaps in some data. Budgetary constraints in some 
TABLe 1: Raw coal quality data (as received).

\begin{tabular}{|c|c|c|c|c|c|c|c|}
\hline & Ash & Moisture & Volatile & Sulfur & Fixed carbon & kJ/kg (BTU/lb) & HGI* $^{*}$ \\
\hline Test 3 & 11.7 & 27.2 & 34.3 & 0.21 & 26.9 & $16,907(7275)$ & 34 \\
\hline Test 4 & 10.2 & 28.7 & 34.3 & 0.19 & 26.8 & $16,865(7257)$ & 31 \\
\hline Test 5 & 11.9 & 25.2 & 35.2 & 0.22 & 27.7 & $17,309(7448)$ & 31 \\
\hline Test 6 & & & & & & & 32 \\
\hline Test 7 & & & & & & & 33 \\
\hline Test 8 & & & & & & & 31 \\
\hline Test 9 & 12.7 & 27.5 & 31.2 & 0.20 & 28.3 & $16,331(7027)$ & 37 \\
\hline Test 10 & 12.2 & 27.4 & 31.7 & 0.19 & 28.7 & $16,479(7091)$ & 34 \\
\hline Test 11 & 11.8 & 27.5 & 32.2 & 0.19 & 28.5 & $16,633(7157)$ & 36 \\
\hline Test 12 & 12.3 & 27.5 & 32.0 & 0.21 & 28.2 & $16,461(7083)$ & 36 \\
\hline Test 13 & 13.5 & 27.5 & 31.3 & 0.21 & 27.8 & $16,349(7035)$ & 36 \\
\hline Test 14 & 12.3 & 27.0 & 31.6 & 0.22 & 29.2 & $16,747(7206)$ & 34 \\
\hline Test 15 & 11.4 & 27.3 & 32.4 & 0.22 & 28.9 & $16,954(7295)$ & 32 \\
\hline Test 16 & 12.7 & 27.1 & 32.3 & 0.21 & 28.0 & $16,540(7117)$ & 33 \\
\hline Test 17 & 14.0 & 27.2 & 31.7 & 0.19 & 27.1 & & 35 \\
\hline Test 18 & 13.9 & 27.2 & 32.3 & 0.19 & 26.7 & & 35 \\
\hline Test 19 & 13.6 & 26.6 & 32.3 & 0.20 & 27.5 & & 36 \\
\hline Test 20 & 12.3 & 26.1 & 33.1 & 0.18 & 28.5 & & 36 \\
\hline Test 21 & 14.1 & 28.2 & 30.8 & 0.20 & 27.0 & & 40 \\
\hline Test 22 & 12.8 & 28.3 & 31.2 & 0.20 & 27.7 & & 40 \\
\hline Test 23 & 13.8 & 29.3 & 32.5 & 0.21 & 24.5 & & 39 \\
\hline Test 24 & 13.3 & 31.3 & 31.8 & 0.20 & 23.6 & & 37 \\
\hline Test 25 & 11.4 & 37.2 & 29.5 & 0.18 & 21.8 & & 35 \\
\hline Test 26 & 13.4 & 29.0 & 33.2 & 0.20 & 24.4 & & 36 \\
\hline
\end{tabular}

${ }^{*}$ Hardgrove grindability index.

TABLE 2: Data on pulverized coal (as received).

\begin{tabular}{|c|c|c|c|c|c|c|c|}
\hline & PSD76 & & & & rized coal & & \\
\hline & PSDT/ & Ash & Moisture & Volatile & $\mathrm{kJ} / \mathrm{kg}(\mathrm{BTU} / \mathrm{lb})$ & Fixed carbon & Sulfur \\
\hline Test 1 & 49 & 15.8 & 14.1 & 38.7 & $19,094(8216)$ & 31.4 & \\
\hline Test 2 & 42 & 14.1 & 12.9 & 39.2 & $20,026(8617)$ & 33.9 & \\
\hline Test 3 & 46 & 13.8 & 15.6 & 40 & $19,329(8317)$ & 30.5 & 0.26 \\
\hline Test 4 & 48 & 12.9 & 16.7 & 40 & $19,324(8315)$ & 30.4 & 0.24 \\
\hline Test 5 & 48 & 13 & 16 & 40.4 & $19,552(8413)$ & 30.7 & 0.25 \\
\hline Test 6 & 50 & 11.1 & 19.9 & 37.6 & $18,838(8106)$ & 31.4 & 0.23 \\
\hline Test 7 & 52 & 11.6 & 18.4 & 37.7 & $19,096(8217)$ & 32.7 & 0.24 \\
\hline Test 8 & 46 & 10.3 & 18.5 & 37.9 & $19,296(8303)$ & 33.3 & 0.23 \\
\hline Test 9 & 55 & 13.6 & 17.5 & 36.3 & $18,564(7988)$ & 32.6 & 0.24 \\
\hline Test 10 & 54 & 14.3 & 13.3 & 38.8 & $19,640(8451)$ & 33.9 & 0.24 \\
\hline Test 11 & 52 & 14.1 & 13.1 & 38 & $19,856(8544)$ & 34.9 & 0.24 \\
\hline Test 12 & 46 & 14.2 & 12.5 & 38.2 & $20,038(8622)$ & 35.2 & 0.24 \\
\hline Test 13 & 51 & 15.5 & 15.5 & 36.7 & $18,941(8150)$ & 32.3 & 0.25 \\
\hline Test 14 & 52 & 14.9 & 15.3 & 37.4 & $19,236(8277)$ & 32.5 & 0.27 \\
\hline Test 15 & 52 & 14.5 & 15 & 37.6 & $19,310(8309)$ & 32.9 & 0.26 \\
\hline Test 16 & 51 & 16.1 & 15.2 & 37 & $18,766(8075)$ & 31.7 & 0.24 \\
\hline Test 17 & 46 & 15.6 & 15.1 & 39.9 & $19,868(8162)$ & 29.4 & \\
\hline Test 18 & 49 & 16.2 & 13.4 & 39 & $19,154(8242)$ & 31.4 & \\
\hline Test 19 & 48 & 15.6 & 12.9 & 39.3 & $19,459(8373)$ & 32.2 & \\
\hline Test 20 & 50 & 15.8 & 13.1 & 38.9 & $19,347(8325)$ & 32.2 & \\
\hline Test 21 & 66 & 15.1 & 17.9 & 37.4 & 18,357 (7899) & 29.6 & \\
\hline Test 22 & 70 & 16.5 & 14.9 & 36.7 & $18,917(8140)$ & 31.9 & \\
\hline Test 23 & 75 & 13.9 & 17.9 & 39 & $19,029(8188)$ & 29.2 & \\
\hline Test 24 & 67 & 13.2 & 18.5 & 40.3 & $18,957(8157)$ & 28.1 & \\
\hline Test 25 & 78 & 14.9 & 18 & 38.1 & $18,671(8034)$ & 29.1 & \\
\hline Test 26 & 81 & 16.3 & 16.9 & 37.8 & $18,713(8052)$ & 29 & \\
\hline
\end{tabular}


TABLE 3: Carbon content (dry basis) of fly ash and bottom ash.

\begin{tabular}{lcc}
\hline & Carbon in fly ash (\%) & Carbon in bottom ash $(\%)$ \\
\hline Test 3 & 3.6 & 18.1 \\
Test 4 & 3.1 & 4.6 \\
Test 5 & 4.1 & 22.6 \\
Test 6 & 3.1 & 17.4 \\
Test 7 & 2.6 & 22.3 \\
Test 8 & 2.7 & 25.4 \\
Test 9 & 3.6 & 5 \\
Test 10 & 3.7 & 5.9 \\
Test 11 & 3.7 & 3.5 \\
Test 12 & 4.2 & 4.3 \\
Test 13 & 2.8 & 6.9 \\
Test 14 & 3 & - \\
Test 15 & 3.4 & 3.4 \\
Test 16 & 3.2 & 4.4 \\
Test 17 & 1.9 & 3.6 \\
Test 18 & 1.9 & 3.6 \\
Test 19 & 2.6 & 5.8 \\
Test 20 & 2.6 & 5.8 \\
Test 21 & 2.4 & 1.9 \\
Test 22 & 2.5 & 0.9 \\
Test 23 & 1.2 & 4.3 \\
Test 24 & 1.3 & 7.1 \\
Test 25 & 1 & 3.2 \\
Test 26 & 0.8 & 5.2 \\
\hline & &
\end{tabular}

years determined what data was collected, with only data that was central to the project being always collected.

Figure 2 (same data as Table 5) shows the relationship between the PSD and efficiency. The efficiency was computed as the ratio of energy generated (from MW data in Table 6) to energy burned (computed from pulverized coal data, Table 2, and coal mass flow data, Table 6). The plot, which includes data from the two tests from [9], shows a negligible correlation between PSD and efficiency. However, it also shows clustering in the data due the formation of two clusters that could be named the coarser grind tests and the finer grind tests, depending on whether they were coarser than a PSD of 60 or not. This is quite convenient for the purpose of this research since it allows the two clusters to be compared. The coarse grind group consisted of 20 tests (Tests 1-20), with an average (and statistically different from the fine group) PSD of 50\% compared to only 6 tests (Tests 21-26) with an average PSD of $73 \%$ for the fine group. Table 8 summarizes the difference between the major results of the two groups of tests, while Table 9 summarizes the difference between the feed coal quality for the two groups. Note that the $t$-test was used to test significance when the data was normally distributed. Otherwise, the Mann-Whitney test was used. Sometimes these statistical tests were not possible if the data did not meet the criteria for the tests. The data shown in Tables 1, 2, 3, 4, 5, 6, 7 were used for the various statistics. For example, the efficiencies for the coarse group (Tests 1-20
TABLe 4: Stack gas emissions data.

\begin{tabular}{lcccc}
\hline & $\mathrm{SO}_{2}(\mathrm{ppm})$ & $\mathrm{NO}_{x}(\mathrm{ppm})$ & $\mathrm{CO}(\mathrm{ppm})$ & $\mathrm{CO}_{2}(\%)$ \\
\hline Test 3 & 113 & 164 & 817 & 11.3 \\
Test 4 & 104 & 158 & 1423 & 11.2 \\
Test 5 & 113 & 175 & 1474 & 10.6 \\
Test 6 & 120 & 151 & 937 & 11.9 \\
Test 7 & 119 & 150 & 918 & 11.9 \\
Test 8 & 131 & 157 & 797 & 11.8 \\
Test 9 & 121 & 147 & 1654 & 11.6 \\
Test 10 & 107 & 145 & 2708 & 11.7 \\
Test 11 & 115 & 149 & 1779 & 11.3 \\
Test 12 & 121 & 150 & 1725 & 11.4 \\
Test 13 & 120 & 153 & 1300 & 11.8 \\
Test 14 & 129 & 156 & 2715 & 11.8 \\
Test 15 & 107 & 165 & 561 & 11.3 \\
Test 16 & 119 & 168 & 1990 & 11.7 \\
Test 17 & 114 & 165 & 363 & 11.2 \\
Test 18 & 115 & 166 & 411 & 11.3 \\
Test 19 & 107 & 161 & 483 & 11.4 \\
Test 20 & 144 & 164 & 549 & 11.5 \\
Test 21 & 137 & 159 & 321 & 12.9 \\
Test 22 & 135 & 153 & 718 & 12.5 \\
Test 23 & 112 & 134 & 1096 & 12.3 \\
Test 24 & 123 & 136 & 1489 & 12.4 \\
Test 25 & 133 & 154 & 221 & 12.4 \\
Test 26 & 136 & 156 & 201 & 12.5 \\
\hline
\end{tabular}

in Table 5) average 23.05\%, while the fine group (Tests 2126 in Table 5) average $23.75 \%$. The difference in efficiency is statistically significant as reported in Table 8 .

The results show a difference in efficiency between the two groups of tests. However, it is very small and could simply be due to the small number of samples in the finer grind group. The test with the highest efficiency $(0.244$ at a PSD of 66) was in this group. Additionally, 7 out of the 20 tests in the coarse group had efficiencies that could be in the finer grind group. The coal quality in the two groups does not provide a clear explanation for this difference. However, that is to be expected since coal quality and combustion are typically not directly related [12].

The difference in the carbon content in fly ash and bottom ash between the two groups would normally be explained as higher loss of carbon from coarse grind combustion. However, [8] reported that low-rank highvolatile content Alaska coal results in complete burn out even for very coarse grinds. Therefore, given the small magnitude of difference, the higher carbon content in fly ash and bottom is explained by the higher fixed carbon content of coals in the coarse grind group. This is because the difference in fixed carbon content of feed coal applies to the entire tons burned, whereas the difference in carbon content of ash applies to only $15 \%$ of the tons burned (since ash constitutes about $15 \%$ of the weight in both groups). Note that conclusions on bottom ash should be made with a caveat: bottom ash sampling conditions were very challenging and could have 
TABLE 5: Efficiencies for the various tests.

\begin{tabular}{lcc}
\hline & PSD76 & Efficiency \\
\hline Test 1 & 49 & 0.2299 \\
Test 2 & 42 & 0.2305 \\
Test 3 & 46 & 0.231 \\
Test 4 & 48 & 0.222 \\
Test 5 & 48 & 0.225 \\
Test 6 & 50 & 0.238 \\
Test 7 & 52 & 0.224 \\
Test 8 & 46 & 0.236 \\
Test 9 & 55 & 0.240 \\
Test 10 & 54 & 0.230 \\
Test 11 & 52 & 0.229 \\
Test 12 & 46 & 0.226 \\
Test 13 & 51 & 0.228 \\
Test 14 & 52 & 0.228 \\
Test 15 & 52 & 0.230 \\
Test 16 & 51 & 0.229 \\
Test 17 & 46 & 0.236 \\
Test 18 & 49 & 0.232 \\
Test 19 & 48 & 0.232 \\
Test 20 & 50 & 0.233 \\
Test 21 & 66 & 0.244 \\
Test 22 & 70 & 0.236 \\
Test 23 & & 0.2323 \\
Test 24 & 51 & 0.2342 \\
Test 25 & 5306 \\
Test 26 & & 0.2377 \\
\hline & &
\end{tabular}

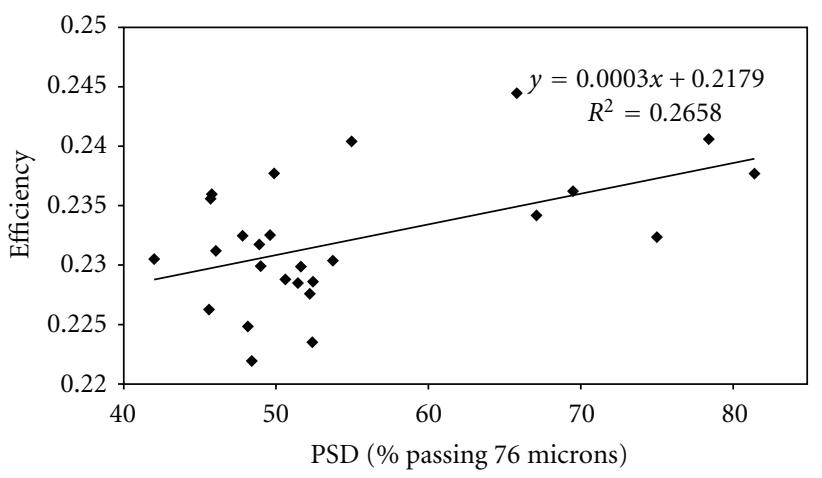

FIGURE 2: Negligible correlation between PSD and efficiency.

impacted bottom ash values. This may explain why bottom ash carbon values are significantly higher than fly ash carbon values in Table 3 for some tests.

$\mathrm{NO}_{x}$ and $\mathrm{CO}$ do not appear to be impacted by PSD (Table 1, and Figures 3 and 4). Both demonstrate significant variability within each test condition. $\mathrm{NO}_{x}$ formation originates with the production of $\mathrm{NO}$, which is formed when the nitrogen in coal or air reacts with oxygen. The authors in $[13,14]$ have identified three mechanisms for the initial formation of NO, thermal NO, prompt NO, and fuel NO. Thermal NO occurs at very high temperatures
TABLE 6: Coal flow rate and MW generated.

\begin{tabular}{lcc}
\hline & Coal flow rate kg/hr & Mean MW generated \\
\hline Test 3 & 22,615 & 28.12 \\
Test 4 & 23,709 & 28.29 \\
Test 5 & 22,828 & 27.92 \\
Test 6 & 22,850 & 28.47 \\
Test 7 & 23,780 & 28.24 \\
Test 8 & 22,460 & 28.45 \\
Test 9 & 22,778 & 28.28 \\
Test 10 & 22,505 & 28.33 \\
Test 11 & 22,377 & 28.26 \\
Test 12 & 22,429 & 28.29 \\
Test 13 & 23,346 & 28.11 \\
Test 14 & 23,084 & 28.11 \\
Test 15 & 22,729 & 28.07 \\
Test 16 & 23,466 & 28.03 \\
Test 17 & 22,635 & 28.14 \\
Test 18 & 22,719 & 28.05 \\
Test 19 & 22,279 & 28.04 \\
Test 20 & 22,365 & 27.99 \\
Test 21 & 22,761 & 28.41 \\
Test 22 & 22,967 & 28.55 \\
Test 23 & 22,663 & 27.88 \\
Test 24 & 22,721 & 28.06 \\
Test 25 & 22,465 & 28.07 \\
Test 26 & 22,688 & 28.05 \\
\hline & &
\end{tabular}

TABLE 7: Hg emissions through the stack.

\begin{tabular}{lcccc}
\hline & \multirow{2}{*}{$\mathrm{Hg}, \mathrm{kg} / \mathrm{hr}(\mathrm{lb} / \mathrm{hr})$} & \multicolumn{3}{c}{ Hg type (percent of total) } \\
& & Particle bound & Oxidized & Elemental \\
\hline Test 23 & 0.000408 & 0.19 & 34.03 & 65.78 \\
$(\mathrm{PSD}=75)$ & $(0.000760)$ & & & \\
Test 24 & 0.000300 & 0.66 & 14.02 & 85.31 \\
$(\mathrm{PSD}=67)$ & $(0.000663)$ & & & \\
\hline
\end{tabular}

when molecular nitrogen combines with oxygen. When the coal contains very little nitrogen, the NO created by this mechanism becomes a significant proportion of the total NO created. Prompt NO occurs when molecular nitrogen combines with hydrocarbons. It, however, forms only a small portion of the total NO formed. Fuel NO, as the name implies, is formed from the nitrogen in the coal and constitutes most of the NO formed. Therefore, the amount of fuel NO formed is highly dependent on the amount of nitrogen in the coal. Thus, since the factors that impact NO generation do not change between the two test groups, there should be no difference in the $\mathrm{NO}_{x}$ generation. Hence, the obtained results are in line with $\mathrm{NO}_{x}$ generation fundamentals.

CO generation in pulverized coal plants is usually not an issue because of thorough mixture of coal particles and oxygen [12]. Coal reactivity, however, can be a factor in CO generation [15], as can excess air be [12]. Neither the 
TABLE 8: Difference in results between the two groups of tests.

\begin{tabular}{|c|c|c|c|c|}
\hline & \multicolumn{2}{|c|}{ Average } & \multirow{2}{*}{$t$-statistic } & \multirow{2}{*}{ Significant difference? } \\
\hline & Coarser & Finer & & \\
\hline Efficiency & 0.2305 & 0.2375 & 3.44 & Yes \\
\hline Unburned carbon (fly ash) & 3.1 & 1.53 & 4.6 & Yes \\
\hline Unburned carbon (bottom ash) & 9.6 & 3.8 & N/A & N/A \\
\hline $\mathrm{SO}_{2}$ & 118 & 129 & 2.5 & Yes \\
\hline $\mathrm{NO}_{x}$ & 158 & 149 & 1.9 & No \\
\hline $\mathrm{CO}$ & 1256 & 674 & 2.1 & No \\
\hline
\end{tabular}

TABLE 9: Difference between the feed coal (pulverized, as received) quality for the two groups of tests.

\begin{tabular}{|c|c|c|c|c|}
\hline & & & t-statistic & Sionificant* difference? \\
\hline & Coarser & Finer & $t$-statistic & Significant difference? \\
\hline Ash (\%) & 14.15 & 14.98 & 1.28 & No \\
\hline Volatile content (\%) & 38.43 & 38.22 & 0.37 & No \\
\hline Volatile content ${ }^{\mathrm{RC}}(\%)$ & 32.5 & 31.5 & 1.66 & No \\
\hline Moisture (\%) & 15.2 & 17.35 & N/A & N/A \\
\hline Moisture $^{\mathrm{RC}}(\%)$ & 27.1 & 30.6 & MWT & Yes \\
\hline Heat Val, kJ/kg (BTU) & $19,337(8320)$ & $18,774(8078)$ & 4.1 & Yes \\
\hline Fixed carbon content & 32.3 & 29.5 & N/A & N/A \\
\hline HGI & 34 & 37.8 & 3.8 & Yes \\
\hline
\end{tabular}

*At 95\% confidence, RC: raw coal, MWT: Mann-Whitney test [11].

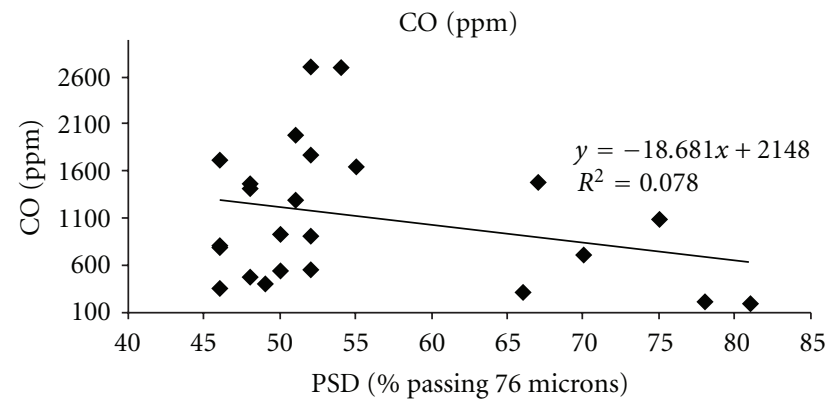

FIgure 3: PSD versus CO.

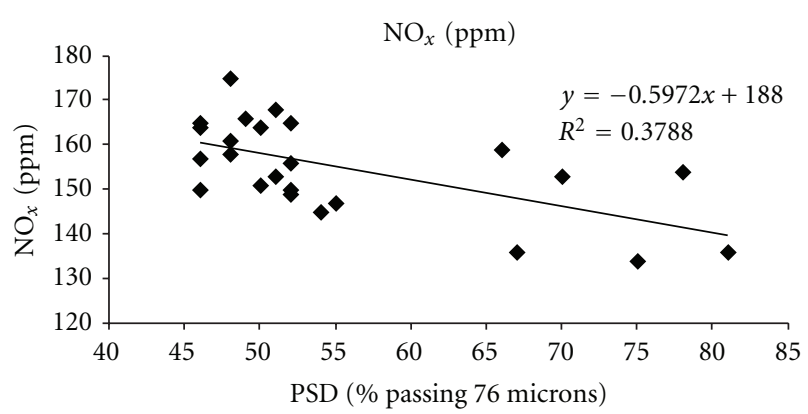

Figure 4: PSD versus $\mathrm{NO}_{x}$.

reactivity (indicated by volatile content) nor the nature of combustion (including operational factors such as oxygen supply [10]) has changed between the two groups of tests, providing no reason for a difference in $\mathrm{CO}$ generation.

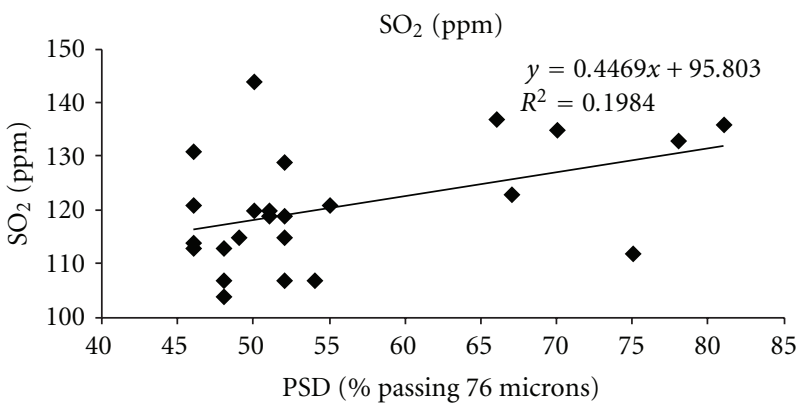

FIGURE 5: PSD versus $\mathrm{SO}_{2}(\mathrm{ppm})$.

$\mathrm{SO}_{2}$ varied somewhat significantly under both test conditions. It seems to be higher for the finer group (Table 8) even though it is not correlated with PSD (Figure 5). The authors in [16] suggested that oxygen concentration, sulfur content, and temperature impacted $\mathrm{SO}_{2}$ production. The sulfur content of feed coal was not the reason for the difference between the $\mathrm{SO}_{2}$ contents of the two groups (see Table 1 for sulfur data) since both groups had an average sulfur content of 0.2. Moisture was explored as a potential reason (since it can contribute oxygen), but it was not found to be correlated to the $\mathrm{SO}_{2}$ content (Figure 5). The higher $\mathrm{SO}_{2}$ content of the finer ground tests could also be explained as due to the low number of samples in that group, though that argument is tenuous given that 4 of the 6 tests had a $\mathrm{SO}_{2}$ concentration above 130, while only 2 out of the 20 tests in the coarse group met that criterion.

The Hg emissions from stack were also studied, though, due to budgetary constraints, $\mathrm{Hg}$ data was collected in only 
two tests. These two tests were conducted one after the other to minimize variance in feed coal quality. Just based on those two tests, it did not seem that the PSD had any impact on $\mathrm{Hg}$ emissions. Hg emissions were very low (close to detection limits) in both tests.

\section{Conclusions}

The broad conclusions from the 26 field tests (including the two in [9]) are as follows.

(1) The plant efficiency was about the same (between 23 and $24 \%$ ) across the particle size distributions.

(2) $\mathrm{SO}_{2}, \mathrm{CO}$, and $\mathrm{NO}_{x}$ levels were essentially the same between the groups, though they varied significantly within each test group. The range was higher for $\mathrm{CO}$ for the coarse group.

(3) $\mathrm{Hg}$ emissions were too low to differentiate between the two groups.

Many pulverized coal plants around the world burn lowrank high-volatile coals, either wholly or in blends. Given the field tested conclusions, these plants could experiment with coarser grinds to extract benefits of coarse grinding-reduced in-plant power consumption and increased coal throughput. For the coal producer, it improves the marketability of their coal.

\section{Acknowledgments}

The authors would like to thank Mr. David Hoffman, superintendent of GVEA's Unit no. 1, and his staff for their significant assistance in conducting this study. Thanks are also due to the US Department of Energy, Arctic Energy Technology Development Laboratory, GVEA, and the Usibelli Coal Mine for their cash or kind support of this study.

\section{References}

[1] R. M. Flores, G. D. Stricker, and S. A. Kinney, "Alaska coal geology, resources, and coalbed methane potential," Tech. Rep. DDS-77, United States Geological Survey, Rolla, Mo, USA, 2004.

[2] J. F. Cudmore, "Coal utilization," in Coal Geology and Coal Technology, C. R. Ward, Ed., pp. 113-150, Blackwell Scientific Publications, Melbourne, Australia, 1984.

[3] M. E. Morgan and P. A. Roberts, "Coal combustion characterisation studies at the International Flame Research Foundation," Fuel Processing Technology, vol. 15, pp. 173-187, 1987.

[4] H. Jungten, "Coal characterization in relation to coal combustion. Part I: structural aspects and combustion," Erdole Kohl, Erdgas, Petrochemie vereinigt mit Brennstoff-Chemie, vol. 40, no. 4, pp. 153-165, 1987.

[5] N. Oka, T. Murayama, and H. Matsuoka, "The influence of rank and maceral composition on ignition and char burnout of pulverized coal," Fuel Processing Technology, vol. 15, pp. 213-224, 1987.

[6] T. F. Wall, "Coal characterization for combustion," in Characterization of Steaming Coals, New South Wales, Ed., pp. 1.1-1.19, University of Newcastle, Institute of Coal Research, Newcastle, Australia, 1985.
[7] G. F. Morrison, "Understanding pulverized coal combustion," Tech. Rep. ICTIS/TR34, IEA Coal Research, London, UK, 1980.

[8] M. Freeman, S. Smouse, and G. Walbert, Preliminary Combustion Test Results of Alaskan/Russian Blends, US Dept of Energy-National Energy Technological Laboratory, Morgantown, WVa, USA, 1996.

[9] D. Malav, R. Ganguli, S. Dutta, and S. Bandopadhyay, "Nonimpact of particle size distribution on power generation at a pulverized coal power plant burning low rank Alaska coal," Fuel Processing Technology, vol. 89, no. 5, pp. 499-502, 2008.

[10] R. Ganguli and S. Bandopadhyay, "Low-rank coal grinding performance versus power plant performance," Final Report FC26-01NT41248, United States Department of Energy, Washington, DC, USA, 2008.

[11] R. Lowry, n.d.,2012 http://faculty.vassar.edu/lowry/utest.html.

[12] A. M. Carpenter, S. Niksa, D. H. Scott, and Z. Wu, Fundamentals of Coal Combustion, IEA Clean Coal Centre, London, UK, 2007.

[13] Z. Wu, NOx control for pulverised coal fired power stations, IEA Clean Coal Centre, CCC/69, London, UK, 2002.

[14] A. M. Eaton, L. D. Smoot, S. C. Hill, and C. N. Eatough, "Components, formulations, solutions, evaluation, and application of comprehensive combustion models," Progress in Energy and Combustion Science, vol. 25, no. 4, pp. 387-436, 1999.

[15] L. Armesto, A. Bahillo, A. Cabanillas et al., "Energy generation from olive-oil industry by-products," in Proceedings of the 6th International Conference on Technologies and Combustion for a Clean Environment, pp. 567-573, Instituto Superior Tecnico, Mechanical Engineering Department, Oporto, Portugal, July 2001.

[16] Y. Li, H. Chen, Z. Zhen, Z. Feng, and J. Dong, "A new SOx simulation model of coal combustion," in Proceedings of the 12th International Conference on Coal Science, p. 5, Australian Institute of Energy, Cairns, Australia, November 2003. 

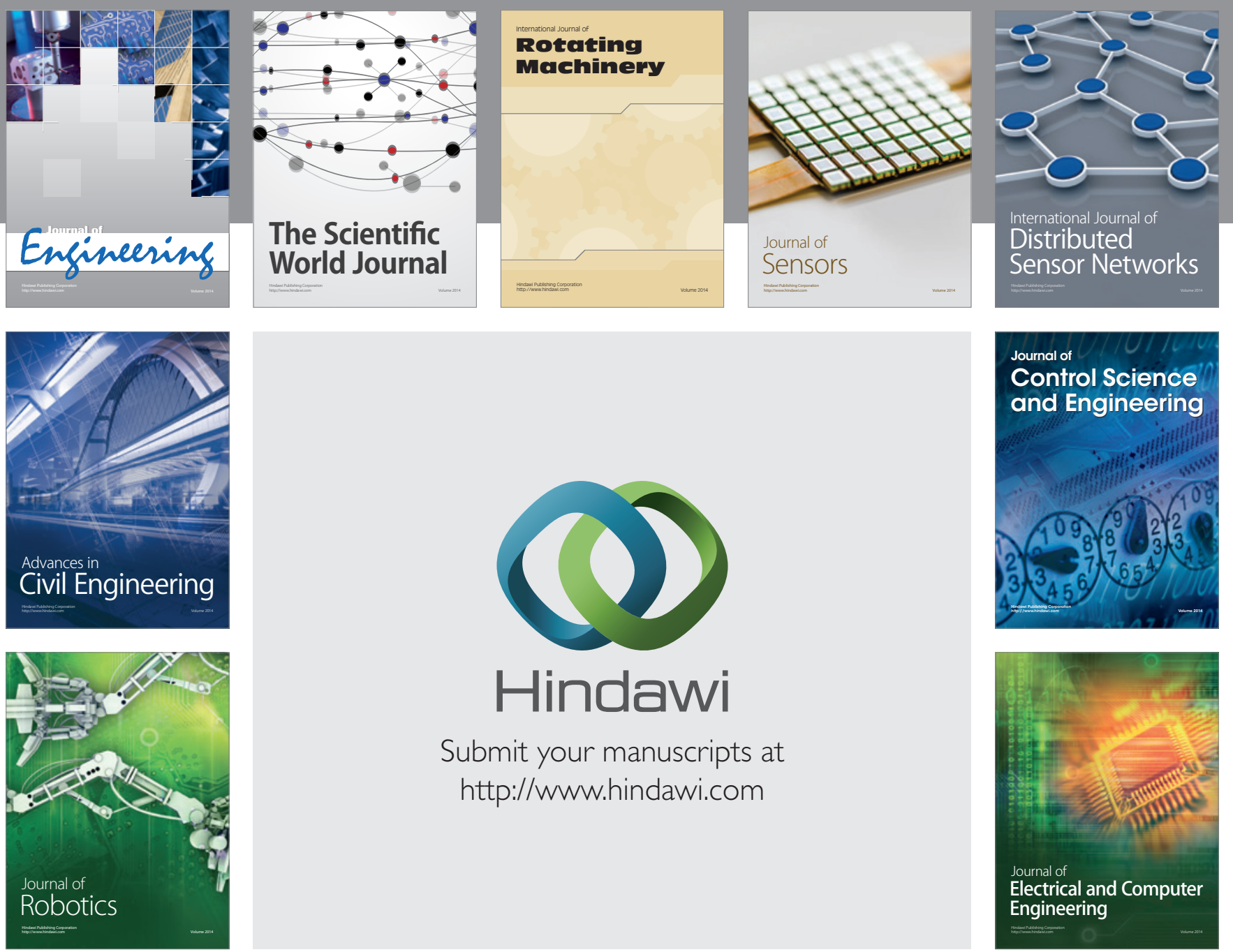

Submit your manuscripts at

http://www.hindawi.com
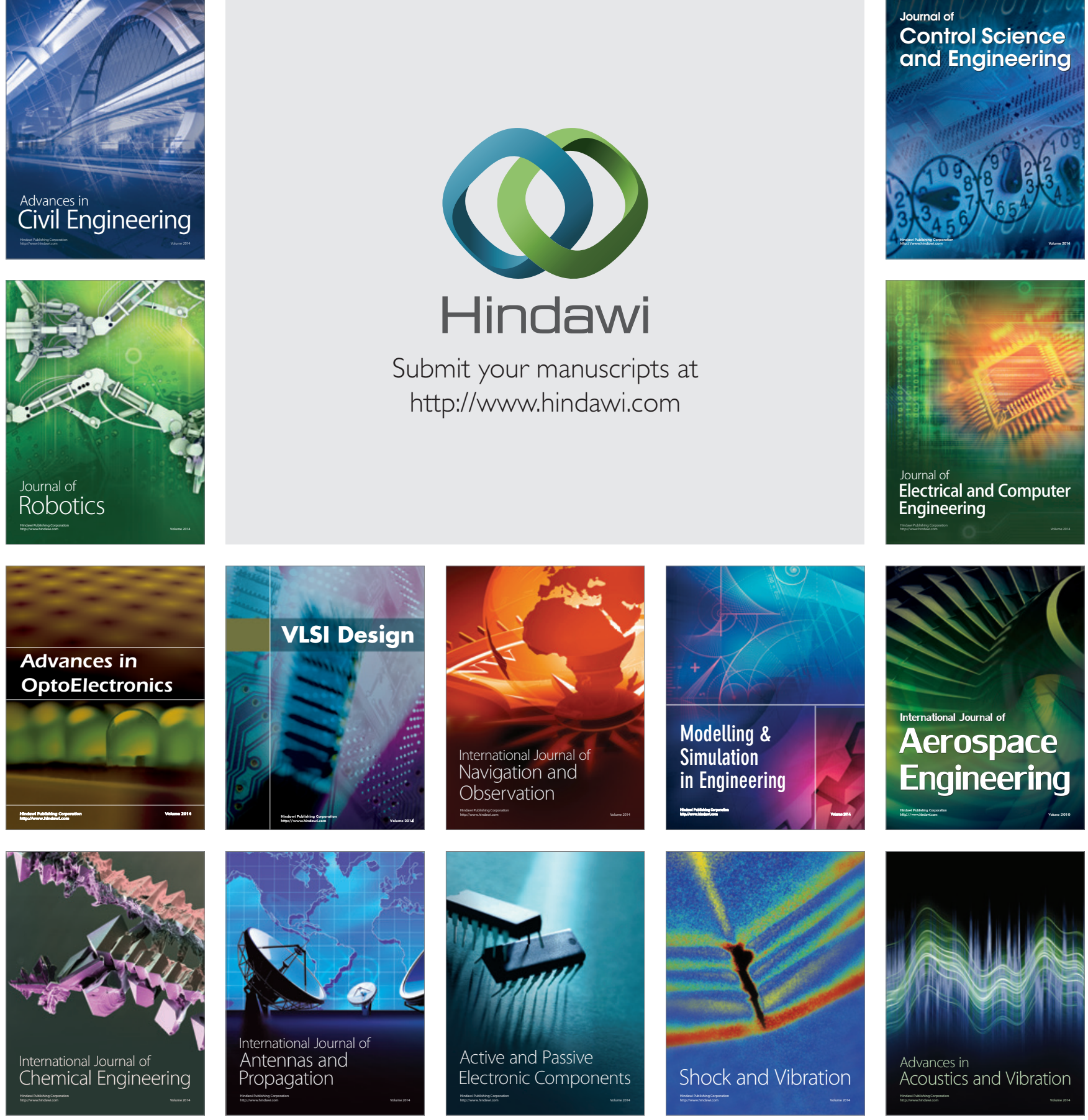